\title{
A ESCOLA INCLUSIVA: SEUS PRESSUPOSTOS E MOVIMENTOS
}

\author{
THE INCLUSIVE SCHOOL: ITS ASSUMPTIONS AND MOVEMENTS
}

\author{
Vera Lúcia Messias Fialho CAPELLINI ${ }^{1}$ \\ Kátia de Abreu FONSECA ${ }^{2}$
}

RESUMO: O estudo desenvolve uma análise teórica sobre a escola inclusiva, considerando a diversidade e fazendo um paralelo entre a educação, a aprendizagem e o desenvolvimento humano. Proporciona uma discussão sobre questões atuais e relevantes, abrangendo os valores e paradigmas que têm norteado a educação brasileira destinada aos alunos, com ênfase na disparidade, sobretudo daqueles que apresentam necessidades educacionais especiais. Enfatiza a importância do convívio e do respeito à diversidade, mostrando a necessidade de flexibilização, modificação e adaptação do ambiente escolar para oferecer a todos, oportunidades e condições de desenvolvimento pleno em uma perspectiva de cultura inclusiva.

PALAVRAS-CHAVE: Educação inclusiva. Desenvolvimento. Necessidades especiais.

ABSTRACT: The study develops a theoretical analysis of the inclusive school, making a parallel with the education and human development. Provides a discussion on current and relevant issues, including the values and paradigms that have guided the Brazilian education intended for students, with emphasis on those that presenting special educational needs. Emphasizes the importance of coexistence and respect for diversity, showing the need for flexibility, adaptation and modification of the school environment to offer everyone opportunities and conditions for full development in an inclusive culture perspective.

KEYWORDS: Inclusive education. Development. Special needs.

\section{Introdução}

Tornamo-nos humanos a partir das relações estabelecidas durante nosso processo evolutivo, ou seja, nosso desenvolvimento. Nesse sentido, podemos dizer que o homem nasce com a raça humana, porém, precisa aprender a se humanizar e essa aprendizagem ocorre por meio das relações que estabelece, partindo das interações com as diferentes pessoas, ou, grupos sociais. Grupo social esse que possui uma determinada língua, um modo de se

1 Universidade Estadual Paulista (Unesp), Faculdade de Ciências, Bauru - SP - Brasil. Professora do Departamento de Educação. E-mail: verinha@fc.unesp.br.

${ }^{2}$ Prefeitura Municipal de Bauru, Secretaria Municipal de Educação, Divisão de Educação Especial. Bauru - SP Brasil. E-mail: kabreufonseca@gmail.com 
organizar e de pensar. Essas pessoas desejam, sonham, realizam, enfim, fazem parte de um contexto cultural determinado.

Entretanto, esse processo pode variar de ser humano para ser humano, para além das características pessoais, pois nem sempre todos têm as mesmas oportunidades.

Consideramos a escola um dos locais propícios para favorecer o desenvolvimento humano, devido às diversas oportunidades criadas e, previamente, planejadas e mediadas pelo professor. Dessa forma, a educação, considerada como um dos direitos fundamentais do ser humano é garantido a todo cidadão, e é consenso que ela pode ser a propulsora do desenvolvimento para quem dela participa.

De tal modo, nesse artigo, objetivamos tecer algumas reflexões teóricas sobre a escola inclusiva, considerando a diversidade e fazendo um paralelo entre a educação, a aprendizagem e o desenvolvimento humano. Parte-se de observações do contexto escolar, com enfoque na educação inclusiva, em que foi possível notar a forma como nossas escolas têm se estruturado, já que nem sempre é favorecido o desenvolvimento de todos os alunos, pois ela não considera as individualidades de cada um. Dessa forma, o estudo é pautado nos pressupostos e movimentos da educação inclusiva, apoiado em análise bibliográfica exploratória.

Logo, tal reflexão dar-se-á num contexto de Educação Inclusiva, entendida como:

[...] um paradigma educacional, fundamentado na concepção de direitos humanos combinando igualdade e diferença como valores indissociáveis, que avança em relação à ideia de equidade formal ao contextualizar as circunstâncias históricas da produção da exclusão dentro e fora da escola. (CAPELLINI, 2009, p. 68).

Seguindo o mesmo princípio, Ainscow (2009) entende que o objetivo da educação inclusiva é eliminar a exclusão social, ou de modo mais realista minimizá-la. Assim, parte do princípio de que a educação constitui direito humano básico e alicerce de uma sociedade mais justa e solidária.

Acreditamos que os profissionais da educação devem se valer da práxis ${ }^{3}$ pedagógica a partir do cotidiano escolar e refletir sobre que medida nossas crenças e atitudes estão colaborando para o pleno desenvolvimento humano de todos os alunos. Assim, reprodução de preconceitos, discriminações e exclusões dos alunos, tornam menos receptivo, agradável e seguro o ambiente escolar.

${ }^{3}$ Práxis - Vázquez apresenta a práxis como atividade material do homem que transforma o mundo natural e social para fazer dele um mundo humano (VÁZQUEZ, 1977). 
Apesar de o discurso ser igualitário, na prática, segundo Saviani (2008), a escola se institucionaliza como solução à ignorância, vista como instrumento para difusão de instrução, transmissão de conhecimentos acumulados pela humanidade e sistematizados, logicamente, mas, infelizmente, não para todos.

Pretendemos assim, com este artigo teórico ampliar o olhar para o papel da escola no desenvolvimento humano pautado no movimento e pressupostos da educação inclusiva.

\section{O desenvolvimento humano a partir das relações estabelecidas com as pessoas e o meio}

De modo geral, o desenvolvimento das crianças começa na família, sendo os responsáveis por elas, seus primeiros educadores. Esse primeiro contexto de desenvolvimento é pouco a pouco ampliado e estas passam a participar de variadas situações de interação com um maior número de pessoas e é a escola a primeira instituição social extrafamiliar. Assim, os componentes da família, amigos e membros de diferentes grupos sociais passam a ter papel importante nas experiências de aprendizagem das crianças e a influenciar em seu desenvolvimento. Essa influência, dos contatos mais imediatos e diretos da criança, a saber, os membros de sua família, amigos, entre outros, dá-se inclusive nas realizações de tarefas básicas ou mais complexas, pois independentemente da idade, nós, seres humanos somos capazes de realizar diversas tarefas, entretanto, também, temos limitações na realização de outras, ou seja, temos nossos limites e possibilidades.

Diferentemente de outros animais que nascem e rapidamente se tornam independentes, nós, seres humanos quando nascemos, dependemos de outras pessoas para sobreviver e nos tornamos autônomos na medida em que desenvolvemos e aprendemos.

Nosso desenvolvimento é um processo contínuo, longo e gradual de mudanças, onde cada pessoa, à sua maneira, ao seu tempo e com variadas interações dá sentido à vida. Portanto, a vida e os valores de uma pessoa só podem ser compreendidos ao considerarmos o seu contexto histórico.

Desta forma, qualquer acontecimento recente, será interpretado de acordo com o modo de pensar, individualmente. O tempo tem um fluxo constante, mas sua organização e ritmo são criados por nossos pensamentos e atividades, tem sua dimensão individual e sua dimensão social, ou seja, cada sociedade divide a existência em períodos e cria um sistema de comportamentos apropriados para cada um.

O ser humano nasce com um repertório inicial de comportamentos e capacidades que irão mediar sua interação com o meio. Contudo, a relação estabelecida com os pares e com o 
meio colaborará com sua formação enquanto homem, humanizado para atuar em diversos aspectos da sociedade. Desta forma, Pino (1995) afirma que a partir do nascimento já não é mais possível separar os aspectos biológicos, dos culturais. Diz ele: “[...] mesmo nos casos extremos - de patologias orgânicas ou mentais profundas — tal separação é impossível, pois as funções orgânicas são, lenta e constantemente, humanizadas." (PINO, 1995, p.265). Segundo esse tipo de abordagem, o desenvolvimento humano é visto como uma:

Síntese entre os aspectos orgânicos (biológicos) e os aspectos psicossociais em jogo na vida do sujeito e postula que, nesse processo, é precisamente a indeterminação genética das ações humanas que abre a possibilidade de sua transformação, da diversidade de suas formas de realização, nas interações sociais. (CARVALHO, 2006, p. 33).

Pletsch (2009) lembra-nos de que para Vygotsky o desenvolvimento se dá por meio da relação e correlação entre as estruturas elementares (reflexos, reações automáticas, associações simples, entre outros) condicionadas, principalmente, por determinantes biológicos e, também, através das estruturas que emergem da interação com a cultura, denominadas de processos psicológicos superiores, onde se encontra a capacidade de formação de conceitos. Estes se referem aos processos que caracterizam o funcionamento psicológico, tipicamente, humano, por exemplo, ações, conscientemente, controladas, como atenção voluntária, memorização ativa, construção de conceitos, pensamento abstrato, etc.

Essas estruturas, por sua vez, são construídas e reconstruídas com base no uso de instrumentos e de signos ao longo de toda a vida do sujeito. Os instrumentos são elementos externos ao indivíduo usados para alcançar objetivos. Por exemplo, o uso do material dourado pela criança na resolução de problemas matemáticos constitui um instrumento que media o processo de apreensão das operações matemáticas envolvidas na tarefa proposta pelo professor. Já os signos são representações internas sobre objetos. Os números, por exemplo, são signos usados para representar o conceito de quantidade. Assim como são signos também a linguagem (oral, gestual, escrita), o desenho, etc. (PLETSCH, 2009, p. 91).

Em todas as sociedades, os seres humanos estabelecem relações entre a cultura e os produtos, as ideias, o modo de pensar e agir, por isso, o desenvolvimento caminha para além da maturação, ou seja, o desenvolvimento de uma criança desde seu nascimento até a vida adulta, em uma determinada sociedade, fornece-lhe um conjunto de objetos, símbolos, significados, costumes, enfim, uma cultura que poderá ser bem diferente de outra. 
Desta forma, o sujeito do conhecimento, para Vygotsky (1987), além de ativo, é interativo, pois, a partir das mediações, consideradas ações externas que moldam a aprendizagem e comportamentos, estimulam novos comportamentos e novas aprendizagens.

A criança ao nascer se integra a uma sociedade já estabelecida de história e cultura de um povo, ou seja, de seus antepassados próximos e distantes, os quais têm fundamental importância no desenvolvimento desse novo participante do grupo social. Desta forma, ele se enquadra e convive com as experiências, hábitos, atitudes, valores e linguagem próprias das pessoas que interagem com a criança, seja no grupo familiar ou social. Grupo social como a escola onde ela se relaciona e interage, o que colabora com a construção da história e da cultura dessa instituição, por conseguinte, de seus alunos.

Assim, o aluno se apresenta como agente de sua própria história, ressignificando-a a cada experiência nova que o leva a novas aprendizagens, contudo, essa condição nos leva a não considerar esse processo como um determinismo histórico cultural.

Podemos, então, concluir que, para a construção do ser humano, ou seja, para o homem humanizar-se, devemos considerar a evolução do indivíduo, ao longo de sua vida e a produção no grupo ao qual ele pertence, bem como, a própria história de vida de cada um, pois sua produção, ou seja, as atitudes, em determinado tempo e espaço, para cada indivíduo, pode variar, de acordo com as interações e experiências.

\section{Exclusão, inclusão e educação}

Desde a antiguidade, temos dificuldade para lidar com questões que fogem ao nosso conhecimento e a um padrão de normalidade.

A história demonstra-nos variados casos de perseguição, intolerância e exclusão de grupos entendidos como "diferentes", submetendo-os às mais diversas formas de homogeneização, violentando-os no que se tem de mais valioso, que é a identidade enquanto ser humano, ou seja, a sua individualidade.

Durante muito tempo, a escola foi concebida como instrumento funcional de formação de uma ordem social e, nesse contexto, consolidava mecanismos de seletividade e de exclusão. Porém, apesar da obrigatoriedade, por lei, oferecendo educação a todo cidadão, ainda no século passado, a permanência dos alunos marginalizados era escassa. As mais variadas condições, sejam sociais, intelectuais, raciais, sexuais, os afastavam da condição de aprendente, devido a uma exclusão velada.

Atualmente, com a disseminação crescente do direito à educação, os grupos 
minoritários, como forma de fazer valer seus direitos de acesso, permanência e sucesso escolar; apresentam-se presentes nesse cenário, demonstrando assim que a educação deve abarcar todos, sem discriminação, ou seja, a escola deve ser inclusiva.

A sociedade passa por transformações e a educação, acompanhando esse movimento, vive, hoje, um momento ímpar - o do novo paradigma da convivência na diversidade, ou seja, de escolas inclusivas.

Exclusão e inclusão são conceitos dialéticos, polarizados, simétricos e compõem uma das grandes preocupações da sociedade atual no campo da educação. Então, podemos dizer que as perspectivas são favoráveis para a educação de todos? Sim, porém não podemos ser pueris em acreditar que o processo dar-se-á de forma imediata e sem participação efetiva da sociedade, pois ainda precedemos de ações para efetivarmos a inclusão social. No entanto, concordamos com Omote (2003, p. 154) quando afirma:

A inclusão é, acima de tudo, um princípio ideológico em defesa da igualdade de direitos e do acesso às oportunidades para todos os cidadãos, independentemente, das posses, da opção religiosa, política ou ideológica, dos atributos anatomofisiológicos ou somatopsicológicos, dos comportamentos, das condições psicossociais, socioeconômicas e da afiliação grupal. Trata-se de um imperativo moral inalienável nas sociedades atuais.

Sendo assim, torna-se fundamental que o homem adapte-se às condições de existência, transformando a sociedade em permanente processo de mudança. Mudança essa que implica construção e reconstrução de ações e atitudes às diversidades. E, é isso que a escola pode prover em seu aspecto pedagógico. É por meio da sua proposta político pedagógica, consciente da realidade e dos prélios imprescindíveis que a população brasileira terá acesso ao mundo da crítica, da reflexão, da análise, do enfrentamento, tão necessário à superação da exclusão social.

Os debates acerca da educação para a diversidade tornam-se cada vez mais intensos, a partir dos quais têm sido recorrentes a urgência de mudanças, tanto no âmbito das políticas quanto das práticas pedagógicas para que se oportunize de fato a educação para todos, a qual adota uma prática que compreenda o desenvolvimento do sujeito numa dimensão histórica, social e cultural que atenda as suas peculiaridades e respeite as diferenças o que o induzirá ao desenvolvimento acadêmico.

Ponderando, então, essas questões referentes à educação, faz-se necessário considerar a cultura inclusiva que tem como base a crença de que todos são responsáveis pela vida da 
respectiva instituição e quaisquer dificuldades ali encontradas são da responsabilidade de todos, e não somente de uma pessoa ou da gestão escolar (SANTOS, 2002a).

A efetivação da escola inclusiva ocorre a partir das ações do coletivo que passam por uma reformulação do ambiente escolar como um todo, desde o espaço físico, dinâmica de sala de aula, currículo, formas e critérios de avaliação.

Assim sendo, tal escola deverá reconhecer e responder às diversas dificuldades de seus alunos, acomodando os diferentes estilos e ritmos de aprendizagem, assegurando uma educação de qualidade para todos, mediante currículos apropriados, modificações organizacionais, estratégias de ensino, recursos e parcerias com suas comunidades. A inclusão na perspectiva de um ensino de qualidade para todos exige da escola novos posicionamentos.

Para tanto, é necessário que a equipe escolar cultive em seu cotidiano, a cultura inclusiva, ou seja, práticas fundamentadas na ética, no respeito às diferenças, na solidariedade, no compromisso de professores, pais, diretores, dirigentes, secretários de educação e comunidade com a aprendizagem dos alunos.

A escola tem nesse cenário, papel fundamental, pois é o espaço no qual se deve, por compromisso ideológico, oferecer e favorecer a todos os alunos, o acesso ao conhecimento e ao desenvolvimento de competências, ou seja, a possibilidade de apreensão do conhecimento, historicamente, produzido pela humanidade e de sua utilização no exercício efetivo da cidadania, pois essas ações contribuem para o desenvolvimento global do aluno como cidadão atuante que respeite as diferenças e, assim, independentemente de qual for a diferença, conviver, exclusivamente, se aprende, convivendo, interagindo.

O desafio da escola consiste em permitir que todos os alunos adquiram conhecimentos que lhes possibilitem transformar-se e transformar o meio em que vive, pautado no princípio da equidade, com igualdade de condições e, ao mesmo tempo, conciliar as singularidades individuais mediante $\mathrm{o}$ acesso à aprendizagem básica, respeitando as diferenças culturais, sociais e individuais. Se isso não ocorrer, a escola estará falhando em seu papel democrático e na formação de cidadãos críticos e atuantes na transformação da sociedade.

Stainback e Stainback (2003, p. 265) descrevem um plano estratégico para que a escola desenvolva a filosofia inclusiva em seu interior:

[...] uma escola inclusiva requer uma crença de que todas as crianças podem aprender e um compromisso de proporcionar a todas as crianças igual acesso a um currículo básico rico e a uma instrução de qualidade [...]; as escolas devem ir além do seu enfoque tradicional, centrado unicamente na 
aprendizagem acadêmica básica [...] ; é importante desenvolver redes de apoio na escola tanto para os professores quanto para os alunos que precisem de estímulo e de assistência [...] ; estabelecer processos contínuos para garantir o planejamento e a monitoração eficientes, efetivos e constantes para os alunos [...]; manter a flexibilidade [...]; utilizar várias abordagens de ensino para satisfazer às necessidades de seus alunos [...] ; comemorar os sucessos e aprender com os desafios; [...] estar a par do processo de mudança. Mas não permitir que ele o paralise [...] a mudança só pode ocorrer em pequenos avanços e que a aceleração do processo pode fazer com que os indivíduos rejeitem as novas práticas e sabotem os esforços de reforma.

No que tange essas diferenças, devemos valorizá-las como elemento enriquecedor no cotidiano escolar. Os alunos aprendem não só o que o professor ensina, intencionalmente, na sala de aula, mas, também, com tudo aquilo que são capazes de interpretar a partir da observação dos comportamentos no ambiente escolar. Assim, devemos fornecer pistas e orientações, buscar a coerência entre aquilo que falamos e as práticas que assumimos, pois, como educadores somos mediadores, informantes e modelos para o desenvolvimento dos alunos. Solicitar que os alunos respeitem a diversidade é uma coisa, demonstrar por atitudes o respeito às diferenças, é outra.

Cada indivíduo tem sua forma singular de compreender o mundo, seus desafios, portanto, qualquer que seja a linguagem (gráfica, gestual, falada ou escrita), ela expressa originalidade do pensamento. Fonseca (2011, p. 87) afirma que:

[...] apesar de a aprendizagem ser um processo altamente individual, pois cada pessoa aprende de determinada forma, em determinado tempo, ela se dá de forma interativa, não só por meio de convivência, discussões, trocas interativas e intelectuais com pessoas semelhantes em sua forma de pensar, agir, interagir, como também em contato com pessoas totalmente diferentes no que se refere aos aspectos de vida pessoal, profissional e até intelectual.

O modo como os alunos falam, acompanham a forma de falar dos grupos que estão inseridos, também, ocorrem com seus comportamentos. Deste modo, é muito importante que os educadores incorporem rotinas que enriqueçam o ambiente linguístico e comportamental dos alunos, envolvendo-os em experiências significativas e funcionais de linguagem e interação.

Quando pensamos em educação, especialmente, em aprendizagem, observamos que existem várias formas de adquirir conhecimentos, habilidades e competências. Uma delas, tanto humana, quanto de outros animais é a forma da tentativa e do erro, ou seja, experimentando várias formas de ação, até encontrar o resultado esperado. 
Outra forma é por imitação. Observamos a conduta do outro e tentamos fazer igual, em alguns casos, podemos receber apoio ou redirecionamento para ajustarmos a ação de tal forma que ele se aproxime da ação imitada quando não estiver correta.

Finalizando temos outra forma de aprendizagem que acontece por meio do ensino intencional, planejado, ou seja, uma pessoa transmite aos outros, conhecimentos, valores, atitudes ou forma de comportar-se, estabelecendo assim uma relação entre ensino e aprendizagem. É uma maneira mais complexa, de estratégias específicas por parte de quem ensina.

Em sentido amplo, a educação compreende os processos formativos que ocorrem no meio social, nos quais os indivíduos estão envolvidos de modo necessário e inevitável pelo simples fato de existirem socialmente; neste sentido, a prática educativa existe numa grande variedade de instituições e atividades sociais decorrentes da organização econômica, política e legal de uma sociedade, da religião, dos costumes, das formas de convivência humana. Em sentido estrito, a educação ocorre em instituições específicas, escolares ou não, com finalidades explícitas de instrução e ensino mediante uma ação consciente, deliberada e planificada embora sem separar-se daqueles processos formativos gerais. (LIBÂNEO, 2008, p. 17).

O ensino intencional pode ocorrer por meio de demonstrações, fornecimento de instruções, pistas, explicações, bem como mediante a organização de um ambiente de aprendizagem, com materiais adequados e sequências de atividades que organizam a apropriação de determinados conhecimentos por parte do aluno.

Libâneo (2008) enfatiza que o ensino é um processo social, integrante de múltiplos processos sociais nos quais estão implicadas dimensões políticas, ideológicas, éticas, pedagógicas, frente às quais se formulam objetivos, conteúdos e métodos conforme opções assumidas pelo educador, cuja realização está na dependência de condições, seja aquelas que o educador já encontra, sejam as que ele precisa transformar ou criar.

Aprender por sua vez é um processo cheio de idas e vindas que envolve tentativas, levantamento de suposições, realização da ação do pensamento e muitos usos da linguagem. Nesse processo, o professor tem papel fundamental, pois é o articulador ou mediador da efetivação da aprendizagem de seus alunos, ele deve além de conhecê-los, ter claro como se estabelece e acontece a aprendizagem deles, este conhecimento influencia de maneira preponderante o que será ensinado, como será ensinado e por que será ensinado.

O conhecimento só é assimilado pelo aluno quando este estabelecer relação entre o que já conhece e o que está tendo oportunidade de conhecer e, fazer a simbolização dando significado a determinado conhecimento, o ajudará a transformar-se e/ou transformar o ambiente em se está inserido. 
Assim, para que os conteúdos apresentados aos alunos sejam significativos, é necessário que o mediador, a saber, o professor, envolva-o no processo de construção do conhecimento, pois existem fatores individuais e subjetivos que interferem no processo de aprendizagem.

A escola por sua vez, a partir do momento em que o aluno nela ingressa, ganha papel de destaque como âmbito educativo, onde ocorre o processo de aprendizagem, promovendo desenvolvimento. Atualmente, os meios de comunicação de massa, sobretudo a televisão e as tecnologias da comunicação e informação (como a internet), também são fontes valiosas de educação quando utilizadas de forma a favorecer a aprendizagem dos alunos.

As diferentes culturas estruturam-se por meio de práticas culturais, isto é, sequências de atividades que se dirigem a determinados objetivos e utilizam certos tipos de materiais e conhecimentos. Várias destas práticas culturais têm a escola como ambiente mais propício para seu ensino. A orientação do professor, o saber que ele já tem sobre o assunto e a indicação de outras fontes de informação mostram-se essenciais na organização dessa prática cultural.

Nessa perspectiva, pensar a educação do ser humano é pensar num contexto de possibilidades de interações sociais intersubjetivas constituídas que se estabelecem num processo de trocas mediadas pelo conhecimento, pela cultura e pela história inerentes a todos os seres humanos, pois, como enfatiza Facci (2006, p. 138).

A educação, de acordo com a vertente da Psicologia russa, é colocada em destaque, por partir do pressuposto de que os seres humanos apropriam-se da cultura para se desenvolver e também para que ocorra o desenvolvimento da sociedade como um todo. Sem a transmissão dos resultados do desenvolvimento sócio-histórico da humanidade seria impossível a continuidade do processo histórico.

Utilizados os mais variados exemplos, fica evidente que a cultura regula os processos de desenvolvimento de seus membros por meio da organização das práticas culturais, isso é feito mediante a orientação dos indivíduos e da realização de aprendizagens específicas. Para isso, as culturas promovem o aparecimento de determinados ambientes específicos de resolução de problemas, organizam a frequência com qual se produz um determinado tipo de acontecimento e regulam o nível de dificuldade das tarefas.

Dentro dessa estrutura, os membros mais experientes dos grupos culturais definem certos conhecimentos como relevantes para que as crianças e jovens participem ativamente 
das diversas práticas culturais. Ao mesmo tempo, tratam de ensinar as crianças e os jovens a dominar esses conhecimentos de modo que ocorra participação.

O conjunto de formas de ajuda por meio do qual um grupo social tenta garantir que seus membros adquiram a experiência cultural do grupo é o que chamamos de educação. Podemos considerar que a educação é a chave que explica as relações entre desenvolvimento, aprendizagem e cultura. Os vários tipos de práticas educativas permitem que os indivíduos adquiram, compartilhem e aprofundem os valores, normas, estratégias e conhecimentos próprios de seu grupo cultural.

As práticas educativas são verdadeiros contextos de desenvolvimento pessoal. Elas possibilitam que as crianças observem e incorporem modelos de atividades, papéis e relações cada vez mais complexos, com a ajuda ou orientação direta de pessoas mais experientes e que as pratiquem, futuramente, de maneira autônoma. Dessa forma, os alunos aprendem e adquirem os conhecimentos e as habilidades imprescindíveis para seu desenvolvimento.

Blanco (2010, p. 291) aponta que,

[...] atualmente, existe uma tendência cada vez maior para os currículos abertos e flexíveis que permitem responder ao duplo desafio da compreensibilidade e da diversidade. Em geral, nessas propostas, são estabelecidas aprendizagens mínimas, para assegurar que todos os alunos adquiram certos elementos básicos da cultura, e as escolas, a partir desses mínimos, constroem uma proposta curricular, adequando, desenvolvendo e enriquecendo o currículo oficial em função das características de seus alunos e do contexto sociocultural de referência.

Por meio de determinadas atividades e práticas educativas, a interação ajuda os indivíduos a adquirir novas aprendizagens específicas e, com elas, a ter acesso a certas capacidades e competências psicológicas. Assim, a educação tem um papel decisivo no processo de desenvolvimento pessoal, pois sem a sua intervenção, o desenvolvimento e o crescimento humano, tais como, os conhecimentos, não seriam possíveis.

A atuação das pessoas mais experientes nos processos de aprendizagem e desenvolvimento das crianças pode ocorrer de muitas maneiras e com diferentes graus de intencionalidade. Quando tratamos dos processos educacionais mais intencionais, com objetivos claros e explícitos como os que acontecem na escola, ou nas relações entre pais e filhos, torna-se importante compreender os mecanismos de ajuda deliberada, planejada que podem levar ao desenvolvimento.

As práticas educativas ajudam os alunos a encontrarem conexões entre o que já conhecem e o que é novo. A aprendizagem que ocorre por meio da intervenção pedagógica é 
a forma mais complexa de aprendizagem e é a escola, o ambiente de excelência para que essa intervenção ocorra, tendo o professor, o papel de interferir no desenvolvimento dos alunos por meio de processos de ensino-aprendizagem.

A intervenção pedagógica pertence ao conjunto das práticas educativas que podem ser definidas como o conjunto de atividades sociais por meio das quais os grupos humanos ajudam seus membros a assimilar a experiência organizada, culturalmente, e a se transformar em agentes de criação cultural. As práticas educativas desempenham papel decisivo na definição dos caminhos do desenvolvimento individual, promovendo-o, orientando-o e dando-lhe conteúdo.

Sob esse aspecto, o papel da educação é criar oportunidades para o desenvolvimento do aluno. Mas, não se cria oportunidades de desenvolvimento a partir do vácuo, há, sempre, uma construção sobre a base do desenvolvimento anterior. Isso significa que para a educação ser realmente promotora de desenvolvimento, é necessário, partir da oportunidade de desenvolvimento no qual o aluno se encontra e realizar atividades que lhes permitam avançar. É importante considerarmos o conhecimento que o aluno já tem, tanto para não oferecer atividades pouco desafiadoras que não lhes permitam avançar e, nem complexas demais, a ponto de não permitir que o aluno, ainda que com ajuda, avance para novos níveis de competência e desenvolvimento, até que realize com autonomia.

O desenvolvimento é um processo promovido, culturalmente. A função da educação é realizar esse trabalho de intermediação entre o indivíduo e seu grupo social. Isso ocorre nas relações entre o aluno e seus pais, seus colegas, seus professores, em situações escolares ou não.

Nessa perspectiva, as interações é que criam desenvolvimento, promovem evolução e mudanças nas pessoas. Os pais, os professores, adultos em geral dão suporte e orientam o desenvolvimento da criança. Cabe ressaltar que o aluno em desenvolvimento não é um ser passivo. Ao mesmo tempo em que condicionam as possibilidades de intervenção do adulto, abrem múltiplas e amplas possibilidades que permitem diferentes aprendizagens que o levam a objetivar o conhecimento aprendido, de forma interna, única e dinâmica.

Ainda nesses casos, cuja aprendizagem se dá por meio da interação da criança com o mundo a sua volta, o papel de outras pessoas continua sendo crucial, uma vez que são os adultos que colocam a disposição das crianças os objetos (jogos, brinquedos, livros, dentre outros), organizam e planejam as atividades das quais elas vão participar. 
Esse modo de aprender serve para destacar a diversidade de meios pelos quais ocorre a aprendizagem e para enfatizar, a importância que o meio humano e social tem na determinação do desenvolvimento.

\section{Movimentos e pressupostos para a efetivação de uma cultura inclusiva}

"A cultura torna-se parte da natureza humana num processo histórico que, ao longo do desenvolvimento da espécie e do indivíduo, molda o funcionamento psicológico do homem." (Marta Oliveira, Vygotsky: Aprendizado e Desenvolvimento: um processo sócio-histórico)

A educação inclusiva é um processo em que se amplia a participação de todos os estudantes nos estabelecimentos de ensino regular. Trata-se de uma reestruturação da cultura, da prática e das políticas vivenciadas nas escolas de modo que estas respondam à diversidade de alunos. É uma abordagem humanística, democrática, que percebe o sujeito e suas singularidades, tendo como objetivos o crescimento, a satisfação pessoal e a inserção social de todos (BRASIL, 2008).

Assim a educação inclusiva deveria garantir a educação para todos e a cada um, pautado no princípio da equidade. Esse conceito está ligado a ideia de pertencimento e responsabilidade compartilhada por parte das esferas do serviço público, nesse caso, a escola.

De acordo com Santos (2002b) ressignificar a escola na proposta inclusiva implica considerarmos muitos aspectos que compõem o cotidiano escolar como variáveis que potencialmente interfiram - positiva ou negativamente - no estabelecimento de uma cultura inclusiva dentro da escola.

Portanto, as escolas devem criar e fomentar uma cultura de escola em que os alunos podem sentir uma sensação de pertencimento através da avaliação de seu contexto cultural e aprender estratégias para lidar com as condições adversas em que vivem. Ideia ratificada por Messias, Muñoz e Luca-Torres (2012/2013).

Quando falamos de todos, estamos falando de cada indivíduo de tantos, em situação desfavorecida, economicamente, ou alvo de estigmas sociais de toda ordem (pobres, negros e pardos, crianças e idosos, mulheres, homossexuais, pessoas com deficiência, os quilombolas, comunidades rurais) que estão, de fato, incluídos no sistema educacional brasileiro.

Pois uma cultura inclusiva é aquela em que prima pelos direitos humanos, respeita as 
diferenças individuais. Quando vista sobre o prisma educacional é aquele ambiente que torna o currículo acessível a todos, prevê respostas para a diversidade com equidade e equiparação de oportunidades em espaços com qualidade e calor humano. Preconiza ajudas e apoios técnicos para fortalecer o desenvolvimento de todas as pessoas. Trata-se de uma educação para todos, visto que uma educação que não é inclusiva não pode ser considerada educação. Podemos, então, nos perguntar, na atualidade, com todos os recursos tecnológicos e metodológicos, a escola não se transformou? A exclusão ainda existe? A cultura inclusiva é preconizada no cotidiano escolar?

Infelizmente, uma cultura inclusiva ainda não é realidade em todas as escolas. É certo que devemos reconhecer as dificuldades enfrentadas nos sistemas de ensino, mas esses evidenciam a necessidade de confrontar as práticas discriminatórias e criar alternativas para superá-las. A educação inclusiva assume, nesse sentido, espaço central no debate acerca da sociedade contemporânea e do papel da escola na superação da lógica da exclusão.

A conquista de ampliação dos direitos sociais e humanos mediante a sistematização de leis, apesar de ser um avanço legal, por si só, não assegura a implementação de ações necessárias à existência de uma sociedade melhor.

O termo diversidade diz respeito à variedade e convivência de ideias, características ou elementos diferentes entre si, em determinado assunto, situação ou ambiente. $\mathrm{O}$ termo está ligado aos conceitos de pluralidade, multiplicidade, diferentes ângulos de visão ou de abordagem, heterogeneidade e variedade. Muitas vezes, também, pode ser encontrada na comunhão de contrários, na intersecção de diferenças, ou ainda, na tolerância mútua. Na esfera da escola e do processo educacional, representa as diferenças nos estilos, ritmos, necessidades, interesses, histórias de vida e motivações de cada aluno(a). Diferenças essas que devem ser (re)conhecidas, compreendidas e valorizadas pelos docentes como um recurso importante para ensinar a todo(a)s estudantes na sala de aula (FERREIRA, 2006).

É importante a compreensão de que, ao longo dos anos, a escola, infelizmente, foi toda estruturada para um padrão de aluno ideal e, ainda hoje, muitas mantêm esse propósito. No entanto, numa perspectiva de educação inclusiva, há que se pensar, urgentemente, em uma escola que respeite e valorize as diferenças sejam elas de cor da pele, de etnia, de diferenças sociais, de gênero, de ter ou não uma deficiência e que, a partir de tais diferenças, ouse implementar práticas pedagógicas mais inclusivas e demais mudanças que se fizerem necessárias para garantir a aprendizagem de todos.

Dessa forma, há que se pensar em um currículo que contemple tais diferenças e oportunize que a aprendizagem seja significativa a partir do contexto a qual está inserido. 
Portanto, o currículo, documento que estabelece seleção, sequência, maneira e tempo de apresentação dos conteúdos, e a avaliação da aprendizagem, devem ser cuidadosamente elaborados, pois os conteúdos devem ser desenvolvidos em situações de aprendizagem, levando-os à emancipação como alunos/cidadãos (FONSECA, 2011).

Logo, para Saviani (2008), currículo tem uma dimensão clara: fazer uma seleção intencional dos conteúdos e da especificidade da escola a fim de promover a socialização do saber e o compromisso com a elevação cultural das massas.

A execução de um currículo voltado ao desenvolvimento acadêmico do aluno corresponde a intenção da escola em efetivar ações que favoreçam o desenvolvimento humano, porém, não deve se restringir apenas às questões academicistas, mas sim, utilizar o currículo acadêmico a favor do desenvolvimento do aluno.

O documento curricular, norteador das práticas pedagógicas, deve ter explicitado os ajustes necessários para atender também às necessidades educacionais de todos os alunos. Porém, e de acordo com Macedo (2007, p.43), a escola se utiliza de um currículo homogêneo, que constitui “[...] ainda um artefato educacional dos mais autoritários e segregacionistas."

Assim, o currículo escolar deve ser considerado mutável, podendo ser adequado, quando necessário, para favorecer a aprendizagem de todos os alunos. Para garantir a oportunidade de aprendizagem a todos. Fonseca (2011) menciona os ajustes curriculares: flexibilização, adequação e a adaptação curricular quando colocadas em práticas asseguram o respeito à individualidade de aprendizagem dos alunos.

As intervenções pedagógicas diferem a partir das necessidades do aluno que, por condições idiossincráticas, não são passíveis de generalização direta. Por essa razão é necessário que o professor conheça o desenvolvimento humano e os processos cognitivos do aprender.

A posição que o professor se apresenta, é de total responsabilidade de conduzir os alunos à construção do conhecimento, transmitindo, mediando e compartilhando saberes. A evolução acadêmica dos alunos depende de sua prática flexível, adequada e adaptada às necessidades cognitivas dos alunos, ou seja, mudança na rotina da qual todos os alunos possam ser beneficiados.

As estratégias de ensino e de avaliação de aprendizagem devem sustentar consistência com a natureza da intervenção no currículo comum, planejada para todos os alunos participantes da sala de aula (BRASIL, 1999). A garantia de acesso aos objetivos, preconizados pelo currículo comum, mostra-se condicionada às modalidades de ajustes curriculares antes apresentados. 
Tentando suprir as necessidades de aprendizagem dos alunos, diversos ajustes curriculares se apresentam como estratégia funcional que podem nortear ações efetivas e eficazes de aprendizagem, abarcando a diversidade que se apresenta nas escolas. Entretanto, a aplicabilidade dos ajustes curriculares, de forma equivocada, foi considerada como exclusiva de alunos com deficiência, por esta razão os conceitos precisam ser minuciosamente estudados e discutidos para que não ocorram distorções nas ações aplicadas à aprendizagem.

De acordo com Blanco (2010, p. 297).

[...] as adaptações curriculares não se restringem apenas aos alunos que apresentam algum tipo de deficiência, mas podem ser requeridas por muitos outros, que por suas condições de desenvolvimento pessoal e por sua experiência educacional, apresentam dificuldades ou defasagem com relação ao currículo correspondente à sua idade.

Estratégias de adequação às necessidades individuais dos alunos são entendidas como adaptação curricular, cuja definição se refere ao "[...] o conjunto de modificações que se realizam nos objetivos, conteúdos, critérios e procedimentos de avaliação, atividades e metodologia para atender às diferenças individuais dos alunos." (RUIZ; PEREJA, 2002, p. 154).

Heredero (2010) considera que as adaptações curriculares ofereçam aos estudantes uma formação integral e plena, atendendo as necessidades manifestadas no processo educativo.

No Brasil, as adaptações curriculares são de cunho político, administrativo, técnico e tecnológico devendo ser implementadas para atender às necessidades educacionais de cada aluno, favorecendo-lhe o acesso ao conhecimento de forma que possa atuar de maneira autônoma e ativa na sociedade.

Avançando o conceito, a flexibilização vincula-se ao matiz de maleabilidade, do que pode modificar-se, flexionar-se, destituindo-a de rigidez tradicional. Dessa forma Beyer (2006, p. 76) conceitua flexibilização curricular e considera que:

O desafio é construir e pôr em prática no ambiente escolar uma flexibilização que consiga ser comum e válida para todos os alunos da classe escolar, porém, capaz de atender aos alunos cujas situações pessoais e características de aprendizagem requeiram uma pedagogia diferenciada. Tudo isso sem demarcações, preconceitos ou atitudes nutridoras dos indesejados estigmas.

A prática pedagógica flexível não deve restringir-se a alteração de atividades 
(acréscimo de atividades complementares ou suplementares na estrutura curricular). É necessário que seja uma ação planejada e relevante na prática pedagógica, em consonância com o Projeto Político-Pedagógico, na perspectiva de um ensino de qualidade que abarque as necessidades de todos os alunos.

A principal população que se beneficia dos ajustes curriculares, são os alunos com deficiência que, por sua condição, é parte constituinte da diversidade em sala de aula. Segundo Kelman (2005), apesar do discurso oficial propor a inclusão, poucas são as escolas brasileiras que utilizam estratégias de adaptação das práticas pedagógicas.

A sua efetivação acadêmica da adaptação curricular ainda não foi estabelecida em sua totalidade. Para efetivar a participação e sucesso acadêmico de todos os alunos, os ajustes devem ser pautados nas tentativas de ações de adequação e flexibilização do currículo que a escola e/ou os professores fazem para que os alunos tenham acesso ao currículo comum, aquele, previamente, organizado e ofertado a todos.

Para concretizar ações inclusivas, dentre elas a execução de ajustes curriculares, a colaboração do profissional da Educação Especial é de suma importância para a participação do aluno na dinâmica escolar, quando pensamos no acesso ao currículo pela variada população que encontramos na escola, pois, a realização dessas modificações é o caminho para o atendimento às necessidades específicas de aprendizagem, ou seja de todos os estudantes com ou sem necessidades educacionais especiais.

Entendendo que o processo educativo hoje precisa abranger uma proposta de educação para todos os indivíduos, independente de suas características físicas, mentais, socais, sensoriais e intelectuais, porém, a partir das características inatas de todos os seres humanos, a teoria sócio histórica dá grandes contribuições para a reestruturação de uma prática pedagógica centrada no indivíduo inserido na coletividade, pois tem elementos teóricos importantes para a busca do entendimento de como se dá o processo de desenvolvimento da pessoa deficiente incluída na educação regular. (DRAGO; RODRIGUES, 2009, p. 55).

\section{Considerações finais}

El objetivo principal del desarrollo es ampliar las opciones de las personas. En principio, estas opciones pueden ser infinitas y cambiar con el tiempo. A menudo las personas valoran los logros que no se reflejan, o al menos no en forma inmediata, en las cifras de crecimiento o ingresos: mayor acceso al conocimiento, mejores servicios de nutrición y salud, medios de vida más seguros, protección contra el crimen y la violencia física, una adecuada cantidad de tiempo libre, libertades politicas y culturales y un sentido de participación en las actividades comunitarias. El objetivo del desarrollo es 
crear un ambiente propicio para que la gente disfrute de una vida larga, saludable y creativa. (MAHBUB UL HAQ, 2012) ${ }^{4}$.

Cada época se impõe e nos impõe desafios diante dos quais nos sentimos, muitas vezes, despreparados. No século que se findou, constatamos a todo o momento, indícios de mudança nos diferentes campos do conhecimento, nas organizações sociais e nas diferentes culturas e sociedades. Eles têm aproximado à escola, levantando questionamentos que demandam reflexões e sobre os quais o coletivo da escola precisa se debruçar, como, por exemplo, essa nova possibilidade de atender à diversidade de alunado na educação, em suas mais variadas situações adversas.

A construção de uma escola democrática, plural e de fato inclusiva que ofereça acesso, permanência e qualidade de ensino para todos os alunos ainda está por fazer. Não obstante, esse sistema escolar desejado em âmbito "macro" é constituído por escolas que, por sua vez, são constituídas de salas de aula "micro" que com sua singularidade, muitas vezes, no seu dia a dia, pedem por auxilio.

Desse modo, a escola ampara, erra, acerta, experimenta um novo jeito de fazer educação, apostando aproximar-se ou até distanciar-se do sistema tão desejado.

Os motivos que impedem o professor de promover a inclusão de todos os alunos na educação comum são multifacetados. São mudanças de cultura, de postura, difíceis de serem ultrapassadas, mas, elas devem ocorrer, com urgência. Resta ter audácia para deixar de usar a escola como instrumento de elitização e exclusão do saber. Resta não ter temor do desafio de ensinar os excluídos que estão chegando a escola. Até porque a legislação nacional já defende e garante a democratização do acesso à educação, porém não é suficiente universalizar a escola. É indispensável, a universalização da relevância da aprendizagem para todos.

Criamos uma civilização que reduz distâncias, que tem instrumentos capazes de aproximar as pessoas ou de distanciá-las, que aumenta o acesso à informação e ao conhecimento, mas que também acentua diferenças culturais, sociais e econômicas. Somente uma educação de qualidade para todos poderá evitar que as diferenças constituam em mais um fator de exclusão.

Quaisquer que sejam os medos e fantasmas e seus prepostos, precisamos superá-los, pois não é mais possível conviver com o modelo de escola e ensino que herdamos do passado.

${ }^{4}$ Creador del Informe sobre Desarrollo Humano. 
O século XXI exige uma nova escola - inclusiva, dinâmica e radicalmente diferente - que além de possibilitar a construção do conhecimento, tenha como papel primordial, que é possibilitar a socialização e o respeito mútuo, o desenvolvimento de valores éticos e a solidariedade.

Partindo do pressuposto de uma educação dialógica, a educação torna-se uma prática compartilhada. Ampliando os limites da sala de aula, o espaço é a escola, a sociedade como um todo, portanto não se trata mais apenas de pensar a "minha prática", trata-se de juntos pensarmos as nossas práticas, compreendê-las e transformá-las, assim podemos pensar em transformação social efetiva, a partir da transformação das práticas de grupos organizados.

A escola atuando a partir da heterogeneidade existente nela, respeitando a individualidade de todos, consequentemente, serão consideradas as diversas maneiras de aprendizagem dos alunos, favorecendo, assim, o desenvolvimento global destes. Entretanto, para ações pontuais, é preciso que os professores tenham conhecimento sobre o desenvolvimento humano, sobre interações sociais para que sejam ofertadas oportunidades de aprendizagem que levem o aluno a construção do seu conhecimento e que tenham suas habilidades potencializadas e assim, desenvolvidas novas competências.

Por fim, é necessário, redobrar esforços para que as escolas possam transformar sua cultura institucional, suas políticas e suas práticas, de forma que respondam, verdadeiramente, à diversidade do desenvolvimento humano. Esse esforço só é possível por meio do trabalho conjunto entre os diferentes atores, no âmbito educativo, articulando com as políticas sociais e econômicas, fundamentado no princípio de que a educação é responsabilidade de todos.

\section{REFERÊNCIAS}

AINSCOW, M. Speech. In: INTERNATIONAL CONFERENCE ON EDUCATION, 48. 2008, Geneva. Inclusive education: the way of the future: final report. Paris: UNESCO, 2009. p.70-73. Disponível em: <http://unesdoc.unesco.org/images/0018/001829/182999e.pdf>. Acesso em: 06 dez. 2016.

BEYER, H. O. Educação inclusiva ou integração escolar? implicações pedagógicas dos conceitos como rupturas paradigmáticas. In: SEMINÁRIO NACIONAL DE FORMAÇÃO DE GESTORES E EDUCADORES, 3., 2006, Brasília. Ensaios pedagógicos. Brasília: MEC/Secretaria de Educação Especial, 2006. p.85-88. Disponível em: <http://portal.mec.gov.br/seesp/arquivos/pdf/ensaiospedagogicos2006.pdf >. Acesso em: 15 abr. 2008.

BLANCO, R. A atenção à diversidade na sala de aula e as adaptações do currículo. In: COLL, C. et al. Desenvolvimento psicológico e educação: transtornos de desenvolvimento e necessidades educativas especiais. 2.ed. Porto Alegre: ARTMED, 2010. 3v, p.290 - 308. 
BRASIL. Ministério da Educação. Secretaria de Educação Especial. Política nacional de educação especial na perspectiva inclusiva. Brasília, 2008.

BRASIL. Parâmetros Nacionais Curriculares: adaptações curriculares. Brasília: MEC/SEF/ SEESP, 1999.

CAPELLINI, V. L. M. O direito de aprender de todos e de cada um. In: MORAES, M. S. S.; MARANHE, E. A. (Org.). Introdução conceitual para a educação na diversidade e cidadania. Bauru: Ed. UNESP-SECAD-UAB, 2009. v.2, p.65-99.

CARVALHO, M. de F. Conhecimento e vida na escola: convivendo com as diferenças. Campinas: Autores Associados; Ijuí: Unijuí, 2006.

DRAGO, R.; RODRIGUÊS, P. S. Contribuições de Vygotsky para o desenvolvimento da criança no processo educativo: algumas reflexões. Revista FACEVV, Espirito Santo, n.3, p.49-56, 2009.

FACCI, M. G. D. Vigotski e o processo ensino-aprendizagem: a formação de conceitos. In: MENDONÇA, S. G. de L.; MILLER, S. (Org.). Vygotsky e a escola atual: fundamentos teóricos e implicações pedagógicas. Araraquara: Junqueira \& Marin, 2006. p.123-147.

FERREIRA, W. B. Inclusão X Exclusão no Brasil: reflexões sobre a formação docente dez anos após Salamanca. In: RODRIGUES, D. (Org.). Inclusão e Educação: doze olhares sobre a educação inclusiva. São Paulo: Summus, 2006. p.212-236.

FONSECA, K. A. Análise de adequações curriculares no ensino fundamental: subsídios para programas de pesquisa colaborativa na formação de professores. 2011. 126f. Dissertação (Mestrado em Psicologia do Desenvolvimento e Aprendizagem) - Universidade Estadual Paulista, Faculdade de Ciências, Bauru, 2011.

HEREDERO, E. S. A escola inclusiva e estratégias para fazer frente a ela: as adaptações curriculares. Acta Scientiarum: Education, Maringá, v.32, n.2, p.193-208, 2010.

KELMAN, C. A. Os diferentes papéis do professor intérprete. Espaço: informativo técnico científico, Rio de Janeiro, v.24, p.25-30, 2005.

LIBÂNEO, J. C. Didática. São Paulo: Cortez, 2008. (Coleção magisterio. Série Formação do Professor).

MACEDO, R. S. Currículo: campo, conceito e pesquisa. Petrópolis: Vozes, 2007.

MAHBUB UL HAQ. Informe sobre desarrollo humano. Disponível em:

<http://hdr.undp.org/es/content/sobre-el-desarrollo-humano/>. Acesso em: 20 jan 2012.

MESSIAS, V. L.; MUÑOZ, Y.; LUCA-TORRES, S. Apoyando la inclusión educativa: um estudio de caso sobre el aprendizaje y convivencia en la educación infantil en Castilla La Mancha. Revista Latinoamericana de Inclusión Educativa, Chile, v.6, n.2, p.25-42, 2012/2013. Disponível em: <http://www.rinace.net/rlei/numeros/vol6-num2/art1.pdf>. Acesso em: 3 dez 2012. 
OMOTE, S. A formação do professor de educação especial na perspectiva da inclusão. In: BARBOSA, R. L. L. (Org.). Formação de educadores: desafios e perspectivas. São Paulo: Ed. da UNESP, 2003. p.153-169.

PINO, A. Semiótica e cognição na perspectiva histórico-cultural. Temas em Psicologia, Ribeirão Preto, n.2, p.31-40, 1995.

PLETSCH, M. D. O ensino itinerante como suporte para a educação inclusiva em escolas da rede municipal de educação do Rio de Janeiro.2009. Dissertação (Mestrado em Educação) - Universidade do Estado do Rio de Janeiro, Rio de Janeiro, 2009.

RUIZ, M. J. C.; PEREJA, E. D. Las adaptaciones curriculares como estrategias de atención a la diversidad. In: GONZÁLES, J. A. T.; PALOMINO, A. S. (Org.). Educación especial: Centros educativos y profesores ante la diversidad. España: Ediciones Pirámide, 2002. p.171192.

SANTOS, M. P. A. Prática da Educação para a inclusão. In: CONGRESSO BRASILEIRO MULTIDISCIPLINAR DE EDUCAÇÃO ESPECIAL, 3., 2002, Londrina. Anais... Londrina: UEL, 2002a. v.3, p.42.

SANTOS, M. P. A. Educação inclusiva: redefinindo a educação especial. Ponto de Vista, Florianópolis, n.3/4, p.103-118, 2002 b.

SAVIANI, D. Pedagogia histórico-crítica: primeiras aproximações. Campinas: Autores Associados, 2008.

STAINBACK, S.; STAINBACK, W. Inclusão: um guia para educadores. Porto Alegre: ARTMED Sul, 2003.

VÁZQUEZ, A. S. Filosofia da Práxis. Rio de Janeiro: Paz e Terra, 1977.

VYGOTSKY, L. S. A formação social da mente. São Paulo: Martins Fontes, 1987.

\section{Como referenciar este artigo}

CAPELLINI, Vera Lúcia Messias Fialho.; FONSECA, Kátia de Abreu. A escola inclusiva: seus pressupostos e movimentos. Doxa: Rev. Bras. de Psicol. Educ., Araraquara, v.19, n.1, p. 107-127, jan./jun. 2017. ISSN: 1413-2060.

Submetido em: 01/01/2017

Aprovado em: 30/03/2017 